\title{
Physico-chemical properties of goor and quality of sugarcane (Saccharum officinarum) as influenced by integrated nutrient management in Bangladesh
}

\begin{abstract}
Sugarcane is the only sugar yielding and economically important crop in Bangladesh. Although, it is a good source of sucrose, alcohol and organic matter waste, soil fertility is declining in sugarcane growing areas. Considering the facts, a field study was carried out during 2014-2015 cropping season to evaluate the impacts of integrated use of different organic and chemical nutrients on the quality of sugarcane. Seven treatments were comprised in this experiment $\left(\mathrm{T}_{1}=\right.$ Control, $\mathrm{T}_{2}=165: 55: 120: 30: 10: 2.5: 4 \mathrm{~kg}$ NPKSMgZnB $\mathrm{ha}^{-1}, \mathrm{~T}_{3}=$ Poultry Litter (PL) @ $5 \mathrm{t} \mathrm{ha}^{-1}+$ 95:51:87:9:10:2.5:4 kg NPKSMgZnB ha ${ }^{-1}, \mathrm{~T}_{4}$ $=$ Cow Dung (CD) @ $15 \mathrm{t} \mathrm{ha}^{-1}+36: 52: 60: 17: 10: 2.5: 4 \mathrm{~kg} \mathrm{NPKSMgZnB} \mathrm{ha}{ }^{-1}, \mathrm{~T}_{5}=$ Press Mud (PM) @ $15 \mathrm{t} \mathrm{ha}^{-1}+$ 10:50:43:0:10:2.5:4 kg NPKSMgZnB ha-1 ${ }^{-1}=$ Mustard Oil Cake (MOC) @ 0.5 $\mathrm{t} \mathrm{ha}^{-1}+$ 140:54:115:25:10:2.5:4 kg NPKSMgZnB ha-1 and $\mathrm{T}_{7}=\mathrm{GM}$ (Green Manure) @ $5 \mathrm{tha}^{-1}+140: 53: 100: 28: 10: 2.5: 4 \mathrm{~kg}$ NPKSMgZnB ha $\left.{ }^{-1}\right)$. The experiment was carried out in a Randomized Complete Block Design (RCBD) with three replications. Results of cane quality parameters, the treatment $\mathrm{T}_{3}$ (PL @ $5 \mathrm{t} \mathrm{ha}^{-1}+$ 95:51:87:9:10:2.5:4 $\mathrm{kg}$ NPKSMgZnB ha ${ }^{-1}$ ) recorded the highest brix (20.9\%), pol in cane (14. 9\%) and sugar yield $\left(15 \mathrm{t} \mathrm{ha}^{-1}\right)$. The goor quality parameters likes sucrose $(80.1 \%)$, colour transmittance $(57.80 \%)$ and goor recovery $(11.21 \%)$ were noticed highest in $\mathrm{T}_{3}$ treatment, which was similar to $\mathrm{T}_{4}$ treatment (CD @ $15 \mathrm{t} \mathrm{ha}^{-1}+36: 52: 60: 17: 10: 2.5: 4 \mathrm{~kg} \mathrm{NPKSMgZnB} \mathrm{ha}{ }^{-1}$ ). On the other hand the lowest reducing sugars $(6.56 \%)$ and ash content $(2.96 \%)$ were also observed in $\mathrm{T}_{3}$ treatment. The results from this experiment revealed that the treatment PL @ $5 \mathrm{t} \mathrm{ha}^{-1}$ + 95:51:87:9:10:2.5:4 kg NPKSMgZnB ha-1 followed by CD @ $15 \mathrm{t} \mathrm{ha}^{-1}+$ 36:52:60:17:10:2.5:4 $\mathrm{kg}$ NPKSMgZnB ha ${ }^{-1}$ provided a scope to supply raw material with juice and goor quality of sugarcane grown in High Ganges River Floodplain soils to sugar industry and goor makers.
\end{abstract}

Keywords: juice quality, organic fertilizer, poultry litter, colour transmittance, sucrose
Volume 5 Issue 6 - 2020

\author{
Md. Shamsul Arefin,' Md. Mokhlesur \\ Rahman, ${ }^{2}$ Md.Abdul Alim, ${ }^{3}$ Md.Ariful Islam ${ }^{4}$ \\ 'Physiology and Sugar Chemistry Division, Bangladesh Sugar \\ crop Research Institute, Bangladesh \\ 2Department of Agricultural Chemistry, Faculty of Agriculture, \\ Bangladesh Agricultural University, Bangladesh \\ ${ }^{3}$ Department of Food Technology and Rural Industries, Faculty \\ of Agricultural Engineering,Agricultural University, Bangladesh \\ ${ }^{4}$ On-Farm Research Division, Bangladesh Agricultural Research \\ Institute, Bangladesh
}

Correspondence: Md. Shamsul Arefin, Physiology and Sugar Chemistry Division, Bangladesh Sugar crop Research Institute, Ishurdi, Pabna, Bangladesh, Email arefinbsri@gmail.com Md.Ariful Islam, On-Farm Research Division, Bangladesh Agricultural Research Institute, Pabna, Bangladesh, Email arifbau06@gmail.com

Received: November 18, 2020 | Published: December 2I, 2020

\section{Introduction}

Sugarcane is a tropical and subtropical giant grass crop belonging to the grass family, Gramineae. Sugarcane shares $0.91 \%$ of total GDP in the national economy sector and $9.11 \%$ of the total value of agricultural output. It occupies only $1.39 \%$ of Bangladesh gross cropped area. ${ }^{1}$ Sugarcane is used for making white sugar and goor in our country. The minimum per capita consumption of sugar is $13.0 \mathrm{~kg}$ or its equivalent quantity of goor $17.0 \mathrm{~kg} .{ }^{2}$ Total sugar need is 1.95 million tons or 2.55 million tons of goor based on 142 million people in our country for the $21^{\text {st }}$ century. Therefore, there is a huge gap of 1.35 million tons of sugar or goor in the country. Sugar production in Bangladesh is much less than that of other sugarproducing countries due to low cane yield and sugar recovery. Due to the fluctuation of the area under sugarcane cultivation, the production of sugarcane fluctuated from year to year. Sugarcane, long duration and large biomass accumulating crop remove substantial quantities of plant nutrients from the soil. Increasing land-use intensity has to result in massive exhaustion of nutrients from the soil. Depletion of soil fertility is a major constraint for sustainable crop production in Bangladesh. Farmers generally use inorganic fertilizers for crop production due to easy access and scarcity of organic fertilizers. Improper and imbalanced use of fertilizers along with cultivation of exhaustive crops like sugarcane causes a detrimental effect on soil properties. Further use of excess nitrogenous fertilizer may cause nitrate contamination in surface and ground water). ${ }^{3}$ As a result soil productivity has come down and concerns like physical, chemical and biological degradation and declining organic matter content are also becoming increasingly relevant. From this aspect, it is urgently needed to increase the yield of sugarcane and sugar recovery. Hence, the combined application of organic and chemical sources of plant nutrients may be done in such a way that the soil fertility is maintained without compromising yield loss. Integrated nutrient management involves the integrated use of chemical fertilizers along with organic fertilizers to increase production and improve soil health without environmental hazards. The concept of integrated nutrient management (INM) included appropriate crop rotations, cover crops, manures, crop residues, fertilizers and conservation tillage. ${ }^{4}$ In Bangladesh, soil fertility status is decreasing day by day due to intensive cultivation of the high yielding crop, little use of organic materials, improper soil and crop management practices as well as the use of higher doses of chemical fertilizers. ${ }^{5}$ Soomro et al. ${ }^{6}$ stated that quality parameters such as Brix, pol, purity, commercial cane sugar and its accumulation in sugarcane were higher with the application of three-fourth of the recommended rate of NPK fertilizer (169-841261) +20 tons press mud ha- ${ }^{-1}$. Incorporating press mud into the soil increased sugar yield and cane juice quality. ${ }^{7}$ This study investigated the effects of INM strategy on the quality of sugarcane as compared to traditional nutrient management to know the effect of either alone or in a combination of organic and chemical fertilizers. To achieve 
the research goal, the present study was designed to investigate the impact of integrated nutrient management on the quality of juice and goor in sugarcane.

\section{Materials and methods}

\section{Description of the experimental site}

The field experiment was carried out at the research field of Bangladesh Sugarcrop Research Institute (BSRI), Ishwardi, Pabna, Bangladesh. The station is situated between $24^{\circ} 06^{\prime} 56.6^{\prime \prime} \mathrm{N}$ latitude and $89^{\circ} 05^{\prime} 17.0$ 'E longitude and situated about $15.5 \mathrm{~m}$ above the mean sea level. The rainfall is heavy during the month of April to September and moderately low rainfall during the month of October to March. The total rainfall occurs within eight months with mean monthly values in the range of $1.13-12.93 \mathrm{~mm}$. Generally, the temperature is moderately high during the month of April to September and moderately low with scant rainfall during October to March. The mean temperature ranges from 13.0 to $27.2^{\circ} \mathrm{C}$. The average sunshine hour of the experiment site varied from 0.16 to 5.11 hours. The site of the experiment belongs to the Sara soil series under the High Ganges River Flood Plain Tract belonging to Agro-Ecological Zone 11 (AEZ 11). The soil of the experimental site was calcareous alluvial soil with low organic carbon $(0.72 \%)$. The soil type of the site was silty loam. The experimental field was a medium high land soil with the well internal drained condition.

\section{Experimental materials}

As a sugarcane variety is a test crop, Isd 39 is largely cultivated by farmers and responds very well to organic sources of nutrients. This variety was selected in addition to the recently released high sugar content. As a high tillering variety, it is tolerant of water logging, flood and drought situations and is the most ideal for sugar production and goor making.

\section{Treatments and experimental design}

The experiment comprised of the combinations with seven treatments was used in this study. The field experiment was laid out in Randomized Complete Block Design (RCBD) with three replications (Table 1).

Table I Treatment details included in the experiment

\begin{tabular}{|c|c|}
\hline $\begin{array}{l}\text { Treatment } \\
\text { abbreviation }\end{array}$ & Treatment description \\
\hline $\mathrm{T}_{1}$ & Contr \\
\hline $\mathrm{T}_{2}$ & | 65:55: | 20:30:1 0:2.5:4 kg NPKSMgZnB ha-1 \\
\hline $\mathrm{T}_{3}$ & PL @ 5 t ha-1 + 95:51:87:9:10:2.5:4 kg NPKSMgZnB ha-1 \\
\hline $\mathrm{T}_{4}$ & $\begin{array}{l}\text { CD @ } 15 \mathrm{t} \mathrm{ha}^{-1}+36: 52: 60: 17: 10: 2.5: 4 \mathrm{~kg} \text { NPKSMgZnB } \\
\mathrm{ha}^{-1}\end{array}$ \\
\hline $\mathrm{T}_{5}$ & PM@ @ $15 \mathrm{t} \mathrm{ha}^{-1}+10: 50: 43: 0: 10: 2.5: 4 \mathrm{~kg}$ NPKSMgZnB ha-1 \\
\hline $\mathrm{T}_{6}$ & $\begin{array}{l}\text { MOC @ } 0.5 \mathrm{t} \mathrm{ha}^{-1}+140: 54: 115: 25: 10: 2.5: 4 \mathrm{~kg} \\
\text { NPKSMgZnB ha-1 }\end{array}$ \\
\hline $\mathrm{T}_{7}$ & $\begin{array}{l}\text { GM @ } 5 \text { t ha }^{-1}+140: 53: 100: 28: 10: 2.5: 4 \text { kg NPKSMgZnB } \\
\text { a }^{-1}\end{array}$ \\
\hline \multicolumn{2}{|c|}{ 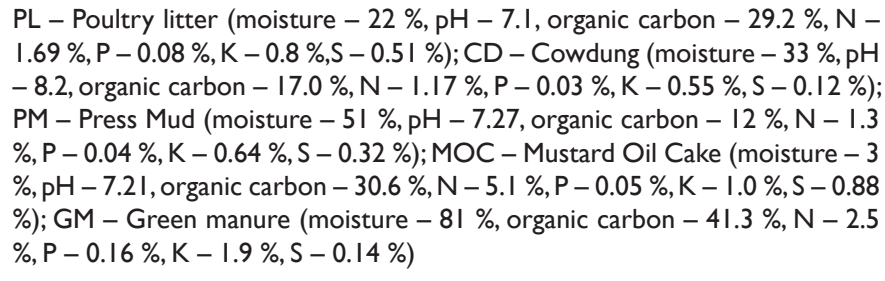 } \\
\hline
\end{tabular}

\section{Agronomic management}

The experimental plot was set as per treatments and design. The settlings of poly bag were planted following spaced transplanting (STP) method. The raised poly bag settlings were transplanted in trenches at $45 \mathrm{~cm}$ distance. The rates of chemical fertilizers for different treatments were calculated on the basis of recommended fertilizer dose (RFD) for high yield goal (HYG) and integrated plant nutrition system (IPNS) based on the composition of each organic waste material and its major nutrient contents. Chemical fertilizers were used at the rates of $165 \mathrm{~kg} \mathrm{~N}, 55 \mathrm{~kg} \mathrm{P}, 120 \mathrm{~kg} \mathrm{~K}, 30 \mathrm{~kg} \mathrm{~S}, 10$ $\mathrm{kg} \mathrm{Mg}, 2.5 \mathrm{~kg} \mathrm{Zn}$ and $4 \mathrm{~kg} \mathrm{~B} \mathrm{ha}^{-1}$ in the form of urea, TSP, MoP, gypsum, magnesium sulfate, zinc sulfate and borax, respectively as recommended dose of sugarcane. Cow dung (CD), poultry litter $(\mathrm{PL})$, press mud (PM), mustard oil cake (MOC) and green manure (dhaincha) were applied as per treatments. All the sources of organics and a full dose of $\mathrm{P}, \mathrm{S}, \mathrm{Mg}, \mathrm{Zn}$ and $\mathrm{B}$ fertilizers were applied in trenches and mixed with soil prior to transplanting of settlings. The basal dose of $\mathrm{N}$ fertilizer (1/3rd) was applied as side-dressing at 30 days after transplanting (DAT). The rest amounts of $\mathrm{N}$ and $\mathrm{K}$ fertilizers were applied as a top dressing in two equal splits at 120 and 180 DAT. In case of green manuring treatments, dhaincha seeds were sown in between two rows of sugarcane at the rate of $25 \mathrm{~kg} \mathrm{ha}^{-1}$ in the month of April. After 45 days, dhaincha was cut into small pieces and mixed into the soil. Irrigation was applied in trenches just after transplanting of the settlings in the plots under STP method to ensure quick and maximum establishment. Supplementary irrigation was also applied after 15, 60, 90 and 120 DAT when the moisture reached $60 \%$ depletion of the field capacity. The soil in trenches was loosened twice at 30 and 60 days after transplanting to prevent the settlings from suffering from soil compaction. All the plots were kept weed-free up to 140 DAT, as the period is considered to be the critical period for crop-weed competition in the sugarcane field. The cultural, mechanical and chemical control measures were done for insect-pests and disease management as and when required. Earthing-up was done three times on 120,150 and 180 DAT. This operation has converted the ridges into furrow and furrow into ridges. Tying was done two times, first in July and then September to keep the clump straight to protect the cane stalks from lodging against the possibility of strong wind. The dried leaves were removed from plants and green leaves on plants were tied together by taking all the canes in one bundle. Cross tying was done by binding two clumps of adjacent rows together. Regarding the planting date and method, the crop was harvested manually at its physiological maturity stage.

\section{Data collection and measurements}

Sugarcane quality parameters: Cane samples were randomly taken from different parts of the plot and made the total number of stalks to 20. Cane samples were crushed by BSRI developed modern cane crusher. Juice samples extracted by means of a power driven sugarcane crusher from 10 canes were selected at random from the net plot area at harvest. Sugarcane juice was chemically analyzed for the following quality parameters:

Brix (\%): Percentage of total soluble solids present in cane juice

Pol (\%) in juice: Percentage of pure sucrose content in cane juice

Purity (\%): Percentage of pure sucrose in dry matter $=\frac{\text { Pol }}{\text { Brix }} \times 100$

Pol (\%) in cane: Percentage of pure sucrose content in whole cane

Total Soluble Solids (TSS) or Brix: Brix readings of the filtered juice samples were recorded with the help of brix hydrometer 
standardized for $20^{\circ} \mathrm{C}$. Juice temperatures were also recorded for necessary temperature corrections. ${ }^{8}$

Pol in juice: Juice samples were clarified as per Horne's dry basic lead acetate method with the help of digital polarimeter (Model: ATAGO AP 300, Japan). Pol readings so recorded were correlated with observed degrees brix with the help of Schmitz's table to obtain the values of pol in juice, which was synonymously used for sucrose content in juice. ${ }^{9}$

The purity of juice: Purity of juice values was computed as per the following formulae.

$$
\text { Purity }(\%)=\frac{\text { Pol in juice }(\%)}{\text { Brix }(\%)} \times 100
$$

Pol in cane: Pol in cane was estimated by Horne's dry basic lead acetate method using polarimeter (Model: ATAGO AP 300, Japan). The corrected pol reading was obtained by comparing the pol reading measured with the corresponding corrected Brix reading referring to Schmitz table and the values were computed as per the following formulae.

$$
\mathrm{Pol}(\%) \text { in cane }=\mathrm{Pol}(\%) \text { in juice } \times \frac{100-(\mathrm{F}+5)}{100}
$$

Where, $\mathrm{F}=$ Fibre in cane $(\%) ; 5=$ constant

Reducing sugars: Lane and Eynon (original) method was used to determine reducing sugars as described by Varma. ${ }^{10}$ Reducing sugar was calculated by the usual formulae:

$$
\text { Reducing sugars }(\%)=\frac{\mathrm{FF}}{\mathrm{TV}} \times \frac{100}{1000} \times \mathrm{DF}
$$

Where, $\mathrm{TV}=$ Titre value; $\mathrm{FF}=$ Fehling factor and $\mathrm{DF}=$ Dilution factor.

Phosphate: Phosphate content of the cane juice was determined by ammonium molybdate method (Varma, 1988). ${ }^{10}$

Fiber: Fibre content of the cane was calculated by using the following formula:

Fibre $(\%)=\frac{\text { A dry weight of the washed shredded cane }(\mathrm{g})}{\text { Fresh weight of the shredded cane }(\mathrm{g})} \times 100$

Sugar yield: Sugar yield was calculated with cane yield and recoverable sucrose using the following formula. ${ }^{9}$

Sugar yield $\left(\mathrm{tha}^{-1}\right)=\frac{\text { Cane yield }\left(\mathrm{t} \mathrm{ha}^{-1}\right) \times \text { Recoverable sucrose }}{100}$

Analysis of goor quality parameters: Goor samples prepared in the laboratory of Physiology and Sugar Chemistry Division at harvest as per the method standardized at Bangladesh Sugarcrop Research Institute (BSRI), Ishurdi, Pabna were analyzed and graded according to quality parameters. The chemical analysis was carried out for certain characteristics to determine the quality and grading according to net rendament values.

Sucrose: Sucrose content was determined by digital polarimeter (Model: ATAGO AP 300, Japan) as done for sucrose of sugarcane juice.
Reducing sugars: Reducing sugars were estimated by titrating goor solution dissolved in $100 \mathrm{~mL}$ water and clarified with dry basic lead acetate with $10 \mathrm{~mL}$ of Fehling's A + B solution according to Lane and Eynon volumetric method. ${ }^{10}$

$$
\text { Reducing sugars }(\%)=\frac{\mathrm{FF}}{\mathrm{TV}} \times \frac{100}{1000} \times \mathrm{DF}
$$

Where, $\mathrm{TV}=$ Titre value; $\mathrm{FF}=$ Fehling factor and $\mathrm{DF}=$ Dilution factor.

Colour transmittance: For colour transmittance in $0.25 \mathrm{~N}$ solutions of goor samples, $6.5 \mathrm{~g}$ goor was dissolved in $100 \mathrm{~mL}$ of water. ${ }^{11}$

Ash: Sulphated ash content in goor was calculated. Carbonated ash content was usually determined by making a deduction of $10 \%$ of sulphated ash. Ash content was expressed as per cent goor basis as indicated below ${ }^{11}$ :

$$
\text { Ash }(\%)=\frac{\text { Weight of ash }}{\text { Weight of goor sample }} \times 100
$$

$\mathrm{pH}$ : Thirteen grams of goor were dissolved in water and made up to $100 \mathrm{~mL}$ volume. $\mathrm{pH}$ solution was determined by $\mathrm{pH}$ meter (Model: Hanna, China).

Goor recovery: Goor recovery was calculated by using the following formulae ${ }^{9}$ :

$$
\text { Goor recovery }(\%)=\frac{\text { Weight of total goor }}{\text { Weight of total cane }} \times 100
$$

Grading based on net rendament (NR) value: Net rendament values were calculated by substituting the values in the formula given below:

Net rendament $(\mathrm{NR})$ value $=$ Sucrose $(\%)-[\mathrm{RS}(\%)+(3.5 \times$ Ash $(\%)$.

Based on NR values, goor samples were classified and graded according to the scale proposed by Jabber ${ }^{11}$.

\section{Statistical analysis}

The experimental data were statistically analyzed through "Statistics 10" computer software. The least significant difference (LSD) at $\mathrm{p}=0.05$ was used to compare treatment means. ${ }^{12}$

\section{Results and discussion}

\section{Total soluble solids or brix, pol in juice and purity}

Integrated use of organic and inorganic fertilizers application had no significant effect on total soluble solid (TSS) or brix of sugarcane juice (Figure 1). The treatment $\mathrm{T}_{3}$ (PL @ $5 \mathrm{tha}^{-1}+95: 51: 87: 9: 10: 2.5: 4$ $\mathrm{kg}$ NPKSMgZnB ha ${ }^{-1}$ ) recorded the highest brix $(20.93 \%)$, while the treatment $\mathrm{T}_{6}$ produced the lowest TSS or brix (20.63\%). However, the use of higher chemical nitrogen decreased in total soluble solids. This might be due to dilution caused by higher dose of chemical nitrogen or due to increase in ash in cane juice. Similar findings were claimed by Bangar et al. ${ }^{13}$ and Bokhtiar and Sakurai,${ }^{14}$ who proved that increasing press mud increased juice brix.

Application of different doses of organic and inorganic fertilizers did not significant influence in pol in juice (Figure 1). Among the treatments, the highest pol in juice $(18.84 \%)$ was noted in treatment $\mathrm{T}_{3}$. Higher results, although not significant, were obtained in the 
treatments that received poultry litter (PL) with chemical fertilizers (PL @ $5 \mathrm{t} \mathrm{ha}^{-1}+$ 95:51:87:9:10:2.5:4 kg NPKSMgZnB ha ${ }^{-1}$ ). Pol in the juice was decreased in the plots where green manure (GM) was applied. The results were in line with the findings mentioned by Arefin et al. ${ }^{1}$ Bokhtiar and Sakurai ${ }^{15}$ also reported similar results, those who found that pol in juice occurred decline due to more $\mathrm{N}$ from (C. juncea) incorporated as green manure so that increased the concentration of $\mathrm{N}$ made plant succulent, which in turn diluted the sucrose.
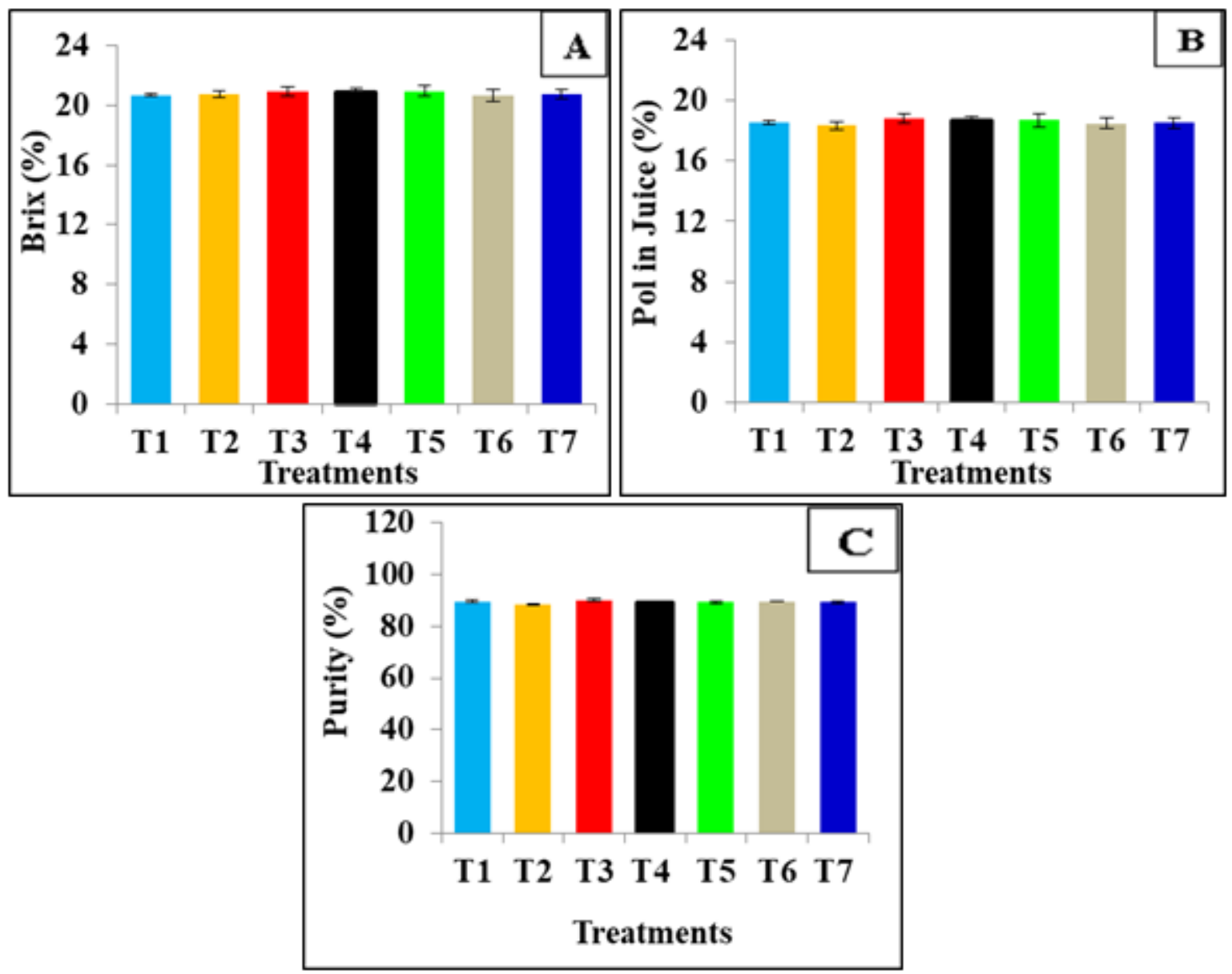

Figure I Effects of integrated nutrient management practices on brix (A), pol in juice $(B)$ and purity $(C)$ of sugarcane. Bars indicate SE ( $n=3)$.

$T_{1}$ C Control, $T_{2}$ 165:55:120:30:10:2.5:4kg NPKSMgZnBha-1, $T_{3}$ Poultry litter @ 5t ha-1 + 95:51:87:9:10:2.5:4kg NPKSMgZnB ha-1, $T_{4-}$ Cowdung @ I5t $\mathrm{ha}^{-1}+$ 36:52:60:17:10:2.5:4kg NPKSMgZnBha-1, T ${ }_{5-}$ Press Mud @ 15t ha-1 + 10:50:43:0:10:2.5:4kg NPKSMgZnB ha-1 ${ }^{-1}$ _ Mustard Oil Cake @ 0.5t ha-1 +

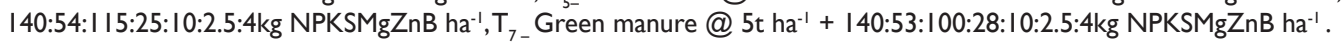

Sugarcane juice purity did not significant influence by different doses of integrated fertilizer application (Figure 1). Results observed that maximum purity $(90.02 \%)$ produced in treatment $\mathrm{T}_{3}$ among all the treatments. While the minimum purity $(88.46 \%)$ was recorded in $\mathrm{T}_{2}$ treatment. Similar trend was recorded as in total soluble solids and sucrose as indicated by Mohammad ${ }^{16}$ and Bokhtiar et al. ${ }^{17}$ They found that reduction in purity was dependent upon sucrose and brix values. A similar conclusion was drawn by Bangar et al. ${ }^{13}$ while comparing with press mud as organic nitrogen fertilizer.

\section{Cane quality parameters}

Application of different integrated fertilizer did not affect on sugarcane juice quality as indicated pol in cane (Table 1). Pol in cane varied from 14.49 to $14.89 \%$. The results found that the treatment $\mathrm{T}$ contained the highest pol in cane $(14.89 \%)$ and it was statistically similar to all other treatments. However, the lowest pol in cane $(14.49 \%)$ was found in the treatment $T_{1}$. Higher results were obtained in the treatments that received chemical fertilizers in combination with poultry litter (PL @ $5 \mathrm{t} \mathrm{ha}^{-1}+$ 95:51:87:9:10:2.5:4 kg NPKSMgZnB $\left.\mathrm{ha}^{-1}\right)$. Application of green manure (GM) plots decreased the values of pol in cane than organic treated plots. The same results were cited by Arefin et al. ${ }^{1}$ and Bokhtiar and Sakurai, ${ }^{17}$ who found that the pol in cane occurred decline due to more $\mathrm{N}$ from incorporated $C$. juncea as green manure so that increased concentration of $\mathrm{N}$ made plant succulent, which in turn diluted the sucrose.

Phosphate content of sugarcane juice significantly varied among the treatments (Table 2). Maximum phosphate content (327.00 $\left.\mathrm{mg} \mathrm{L}^{-1}\right)$ produced in treatment $\mathrm{T}_{4}$ followed by $\mathrm{T}_{3}\left(326.85 \mathrm{mg} \mathrm{L}^{-1}\right)$, which was statistically similar. While, treatment $\mathrm{T}_{1}$ (control) produced the lowest phosphate content $\left(319.67 \mathrm{mg} \mathrm{L}^{-1}\right)$ in sugarcane juice. The treatments $\mathrm{T}_{6}$ and $\mathrm{T}_{7}$ with the values of 325.26 and $324.97 \mathrm{mg} \mathrm{L}^{-1}$, respectively were found similar effect on phosphate content of sugarcane juice. Arefin et al. ${ }^{1}$ noticed the same results who explained that the lower dose of chemical nitrogen in combination with organic fertilizer increased phosphate content in sugarcane juice. 
Table 2 Effects of integrated nutrient management (INM) on cane quality parameters

\begin{tabular}{llll}
\hline Treatments & Pol in cane (\%) & Phosphate $\left(\mathrm{mg} \mathrm{L}^{-1}\right)$ & Reducing sugars (\%) \\
\hline $\mathrm{T}_{1}$ & 14.49 & $319.67 \mathrm{~d}$ & $0.26 \mathrm{a}$ \\
$\mathrm{T}_{2}$ & 14.63 & $322.67 \mathrm{c}$ & $0.25 \mathrm{a}$ \\
$\mathrm{T}_{3}$ & 14.89 & $326.85 \mathrm{a}$ & $0.19 \mathrm{c}$ \\
$\mathrm{T}_{4}$ & 14.77 & $327.00 \mathrm{a}$ & $0.20 \mathrm{bc}$ \\
$\mathrm{T}_{5}$ & 14.75 & $323.00 \mathrm{c}$ & $0.24 \mathrm{ab}$ \\
$\mathrm{T}_{6}$ & 14.64 & $325.26 \mathrm{~b}$ & $0.20 \mathrm{bc}$ \\
$\mathrm{T}_{7}$ & 14.61 & $324.97 \mathrm{~b}$ & $0.24 \mathrm{ab}$ \\
LSD at 0.05 & $\mathrm{NS}$ & 0.88 & 0.04
\end{tabular}

Figure(s) having common letter(s) in a column did not differ significantly at $5 \%$ level of significance

$T_{1}$ C Control, $T_{2}$ 165:55:120:30:10:2.5:4 kg NPKSMgZnBha-1, $T_{3}$ _Poultry litter @ 5 t ha l $^{-1}$ 95:51:87:9:10:2.5:4 kg NPKSMgZnB ha ${ }^{-1}, T_{4-}$ Cowdung @ I5 t $\mathrm{ha}^{-1}+$ 36:52:60:17:10:2.5:4 kg NPKSMgZnBha-1, T ${ }_{5-}$ Press Mud @ $15 \mathrm{t} \mathrm{ha}^{-1}+$ 10:50:43:0:10:2.5:4 kg NPKSMgZnB ha-1, T ${ }_{6}$ Mustard Oil Cake @ 0.5 t ha ${ }^{-1}+$ 140:54: I 15:25:10:2.5:4 kg NPKSMgZnB ha-1, $T_{7-}$ Green manure @ 5 t ha h $^{-1}$ 140:53:100:28:10:2.5:4 kg NPKSMgZnB ha ${ }^{-1}$

Reducing sugars exhibited significant differences among the fertilizer treatments (Table 2). It was seen that the content of reducing sugars in sugarcane juice ranged from 0.19 to $0.26 \%$. The $\mathrm{T}_{3}$ treatment gave the lowest reducing sugars $(0.19 \%)$ content and it was statistically similar to the treatments $\mathrm{T}_{4}(0.20 \%)$ and $\mathrm{T}_{6}(0.20 \%)$. The highest reducing sugars $(0.26 \%)$ content was recorded significantly in $\mathrm{T}_{1}$ treatment. The $\mathrm{T}_{1}$ treatment produced the highest reducing sugars content due to unripened cane as well as low recovery, while the content of reducing sugars $(0.19 \%)$ was lowest due to higher purity and sugar recovery. Similar findings were reported by Hussain et al., ${ }^{18}$ who found that the higher reducing sugars in the juice also increased its concentration in goor.

\section{Fibre and sugar yield}

The fiber content of sugarcane was differed significantly due to application of different organic and inorganic nutrient management treatments (Table 2). Among the treatments, $\mathrm{T}_{1}$ (control) gave the highest fibre content $(16.84 \%)$ and the lowest fibre value $(15.51 \%)$ was produced in $\mathrm{T}_{7}$ treatment, which was statistically as par with $\mathrm{T}_{3}(15.66 \%)$ and $\mathrm{T}_{4}(15.76 \%)$ treatments. Furthermore, the lowest fibre content $(16.84 \%)$ was recorded by the treatment $T_{1}$ treatment. The softness and juiciness of sugarcane mainly depends on its fibre content. Higher is the fibre content; lower is the juice extraction and cane quality. Higher fibre content leads to higher bagasse production and lower juice extraction resulting higher loss of pol in bagasse. ${ }^{20}$ These were agreement with the findings of Bokhtiar et al. ${ }^{17}$ who stated that the integrated use of organic and inorganic fertilizers decreased fiber content in cane. Arefin et al. ${ }^{1}$ also mentioned the same results.

Sugar yield was significantly influenced by the application of integrated nutrient management treatments (Table 3). Higher sugar yield was produced by fertilizer treated plots than control plot $\left(\mathrm{T}_{1}\right)$. The highest sugar yield $\left(14.95 \mathrm{tha}^{-1}\right)$ was recorded in the treatment $\mathrm{T}_{3}$ and was not significant difference over $\mathrm{T}_{4}$ treatment. Sugar yield in $\mathrm{T}_{3}$ and $\mathrm{T}_{4}$ treatments with values of 14.95 and $13.22 \mathrm{t} \mathrm{ha}^{-1}$, respectively were statistically as par. The treatments $\mathrm{T}_{4}, \mathrm{~T}_{6}$ and $\mathrm{T}_{7}$ were also similar on sugar yield with the values of $13.22,10.79$ and $10.52 \mathrm{tha}^{-1}$, respectively. Sugar yield $\left(6.21 \mathrm{tha}^{-1}\right)$ was recorded in the treatment $\mathrm{T}_{\mathrm{f}}$ (control), which was significantly lower as compared to the fertilizer treatments. The results were in agreement with the findings of Arefin et al., ${ }^{1}$ who mentioned that poultry litter application with inorganic fertilizer increased sugar yield. Bangar et al. ${ }^{13}$ reported the increase in sugar yield with varying levels of organic fertilizer application along with chemical fertilizer. It was also found that the integrated use of press mud with inorganic fertilizers increased sugar yield. ${ }^{17}$

Table 3 Effects of integrated nutrient management (INM) on fibre and sugar yield of sugarcane

\begin{tabular}{lll}
\hline Treatment $^{1}$ & Fibre (\%) & Sugar yield $\left(\mathbf{t ~ h a}^{-1}\right)$ \\
\hline$T_{1}$ & $16.84 \mathrm{a}$ & $6.21 \mathrm{~d}$ \\
$\mathrm{~T}_{2}$ & $16.52 \mathrm{~b}$ & $8.79 \mathrm{~cd}$ \\
$\mathrm{~T}_{3}$ & $15.66 \mathrm{~d}$ & $14.95 \mathrm{a}$ \\
$\mathrm{T}_{4}$ & $15.76 \mathrm{~d}$ & $13.22 \mathrm{ab}$ \\
$\mathrm{T}_{5}$ & $16.36 \mathrm{bc}$ & $10.45 \mathrm{c}$ \\
$\mathrm{T}_{6}$ & $16.16 \mathrm{c}$ & $10.79 \mathrm{bc}$ \\
$\mathrm{T}_{7}$ & $15.51 \mathrm{~d}$ & $10.52 \mathrm{bc}$ \\
LSD at 0.05 & 0.26 & 2.71
\end{tabular}

Figure(s) having common letter(s) in a column did not differ significantly at $5 \%$ level of significance

\section{Physical properties of goor}

The application of integrated use of organic and chemical fertilizer was significantly influenced by physical properties of goor (Table 4). Treatments $T_{2}, T_{3}, T_{4}, T_{5}, T_{6}$ and $T_{7}$ showed hard and $T_{1}$ showed moderately soft texture in goor. In respect of crystalline in nature of goor, treatments $\mathrm{T}_{2}, \mathrm{~T}_{3}, \mathrm{~T}_{4}, \mathrm{~T}_{5}$ and $\mathrm{T}_{6}$ produced good crystalline nature. While treatments $T_{1}$ and $T_{7}$ recorded non-crystal and moderately crystal in nature. Furthermore, the golden colour observed in $\mathrm{T}_{2}, \mathrm{~T}_{3}$, $\mathrm{T}_{4}, \mathrm{~T}_{5}, \mathrm{~T}_{6}$ and $\mathrm{T}_{7}$ treatments and $\mathrm{T}_{1}$ showed brown colour of goor in solid state. On the other hand, sweetest of goor produced by the treatments $\mathrm{T}_{2}, \mathrm{~T}_{3}, \mathrm{~T}_{4}, \mathrm{~T}_{5}, \mathrm{~T}_{6}$ and $\mathrm{T}_{7}$ but $\mathrm{T}_{1}$ treatment slightly salty taste was found. 
Table 4 Effects of integrated nutrient management (INM) on physical properties of goor

\begin{tabular}{lllll}
\hline Treatments' & Texture & Crystalline in nature & Colour in solid state & Taste \\
\hline $\mathrm{T}_{1}$ & Moderately Soft & Non-crystal & Brown & Slightly salty \\
$\mathrm{T}_{2}$ & Hard & Good crystal & Golden & Sweety \\
$\mathrm{T}_{3}$ & Hard & Good crystal & Golden & Sweety \\
$\mathrm{T}_{4}$ & Hard & Good crystal & Golden & Sweety \\
$\mathrm{T}_{5}$ & Hard & Good crystal & Golden & Sweety \\
$\mathrm{T}_{6}$ & Hard & Good crystal & Golden & Sweety \\
$\mathrm{T}_{7}$ & Hard & Moderately Crystal & Golden & Sweety \\
\hline
\end{tabular}

\section{Chemical properties of goor}

The sucrose content of goor significantly influenced by different integrated nutrient management treatments (Table 5). Treatment $\mathrm{T}_{3}$ had the highest sucrose content of goor $(80.14 \%)$ and it was statistically similar to the treatment $\mathrm{T}_{4}(79.67 \%)$. However, the treatment $\mathrm{T}_{1}$ (control) showed the lowest sucrose content $(75.80 \%)$. It may be maintained that sucrose per cent being the main sweetening factor of goor and good quality goor should have high sucrose content. These results cited that minimum sucrose content of goor produced in chemical fertilizers alone treatment and maximum sucrose content produced in integrated fertilizer use treatment. Similar findings were reported by Keshaviah. ${ }^{19}$

Table 5 Effects of integrated nutrient management (INM) on chemical properties of goor

\begin{tabular}{llll}
\hline Treatments' $^{\prime}$ & Sucrose (\%) & Reducing sugars (\%) & Colour transmittance $\mathbf{( 0 . 2 5 ~ N )}$ \\
\hline $\mathrm{T}_{1}$ & $75.80 \mathrm{~d}$ & $6.77 \mathrm{ab}$ & $45.83 \mathrm{~b}$ \\
$\mathrm{~T}_{2}$ & $78.02 \mathrm{c}$ & $6.80 \mathrm{a}$ & $51.58 \mathrm{ab}$ \\
$\mathrm{T}_{3}$ & $80.14 \mathrm{a}$ & $6.56 \mathrm{c}$ & $57.80 \mathrm{a}$ \\
$\mathrm{T}_{4}$ & $79.67 \mathrm{ab}$ & $6.58 \mathrm{bc}$ & $56.54 \mathrm{a}$ \\
$\mathrm{T}_{5}$ & $77.77 \mathrm{c}$ & $6.74 \mathrm{abc}$ & $52.20 \mathrm{ab}$ \\
$\mathrm{T}_{6}$ & $79.4 \mathrm{l} \mathrm{b}$ & $6.73 \mathrm{abc}$ & $54.70 \mathrm{a}$ \\
$\mathrm{T}_{7}$ & $78.17 \mathrm{c}$ & $6.69 \mathrm{abc}$ & $53.98 \mathrm{a}$ \\
$\mathrm{LSD}$ at 0.05 & 0.6944 & $0.195 \mathrm{I}$ & 6.82 \\
\hline
\end{tabular}

Reducing sugars of goor were significantly influenced by the application of different integrated fertilizers treatments (Table 5). Treatment $\mathrm{T}_{3}$ indicated minimum reducing sugars $(6.56 \%)$ in goor and it was at par the treatments $\mathrm{T}_{4}, \mathrm{~T}_{5}, \mathrm{~T}_{6}$ and $\mathrm{T}_{7}$. On the contrary, the treatment $\left(\mathrm{T}_{2}\right)$ mentioned maximum reducing sugars $(6.80 \%)$ in goor, which was not identical to the treatments $\mathrm{T}_{1}, \mathrm{~T}_{5}, \mathrm{~T}_{6}$ and $\mathrm{T}_{7}$. Goor containing higher reducing sugars percent generally discourage because it is hygroscopic, poor quality and low shelf-life. The reducing sugars in $\mathrm{T}_{2}$ treatment were found highest due to unripened and lower purity of cane, while, the lowest reducing sugars were observed in $\mathrm{T}_{3}$ treatment due to higher purity. Hussain et al. ${ }^{18}$ cited the same findings who observed that the highest reducing sugars in sugarcane juice increased its concentration in goor. Organic sources of nutrients have brought about reduced content of reduced sugars owing to their steady and continuous supply of nutrients particularly nitrogen, which was responsible for reducing sugar content. The inorganic nitrogen at sugar accumulation stage resulted in accumulation of reducing sugars at higher concentration. Arefin et. al. ${ }^{1}$ described the same results.
Application of different integrated fertilizers treatments significantly differed on colour transmittance of goor (Table 5). The treatment $\mathrm{T}_{3}$ showed the maximum colour transmittance $(57.80 \%)$ of goor. The treatments $\mathrm{T}_{3} \mathrm{~T}_{4} \mathrm{~T}_{6} \mathrm{~T}_{7} \mathrm{~T}_{5}$ and $\mathrm{T}_{2}$ with the respective values of $57.80,56.54,54.70,53.98,52.20$ and $51.58 \%$ were observed statistically similar. The lowest color transmittance of goor $(45.83 \%)$ was found in the treatment $\mathrm{T}_{1}$ (control). Light-coloured goor is always preferred by consumers for eating purposes, and good quality goor is characterized by light colour. The use of organic fertilizer with chemical fertilizers increased sucrose content and decreased reducing sugars level in goor. This might be due to concentration caused by higher dose of organic nitrogen or due to increase in colour transmittance in goor. These results were agreed with the findings of Arefin et. al.'

\section{$\mathrm{pH}$, ash and goor recovery}

The $\mathrm{pH}$ was significantly influenced by the practice of integrated nutrient management treatments (Table 6). The highest $\mathrm{pH}$ value 
(5.75) of goor was found in the treatment $\mathrm{T}_{6}$, which was at par to all other treatments except the control treatment $\mathrm{T}_{1}$. Similarly, the lowest $\mathrm{pH}$ value (5.58) of goor was obtained from the treatment $\mathrm{T}_{1}$ (control) but it was similar to $\mathrm{T}_{2}, \mathrm{~T}_{3}, \mathrm{~T}_{4}, \mathrm{~T}_{5}$ and $\mathrm{T}_{7}$ treatments. Lower $\mathrm{pH}$ indicates acidic. Table 5 showed that $\mathrm{pH}$ value of goor prepared from the treatments (Except $\mathrm{T}_{1}$ ) which was equivalent to neutral $\mathrm{pH}$, and this type of goor was suitable for consumption. Results agree with findings obtained by Arefin et. al. ${ }^{1}$

Table 6 Effects of integrated nutrient management (INM) on pH, ash and goor recovery

\begin{tabular}{llll}
\hline Treatments & $\mathbf{p H}$ & Ash (\%) & Goor recovery (\%) \\
\hline $\mathrm{T}_{1}$ & $5.58 \mathrm{~b}$ & $3.57 \mathrm{a}$ & $10.13 \mathrm{~b}$ \\
$\mathrm{~T}_{2}$ & $5.67 \mathrm{ab}$ & $3.36 \mathrm{ab}$ & $10.27 \mathrm{~b}$ \\
$\mathrm{~T}_{3}$ & $5.72 \mathrm{ab}$ & $2.96 \mathrm{~b}$ & $11.2 \mathrm{I} \mathrm{a}$ \\
$\mathrm{T}_{4}$ & $5.7 \mathrm{ab}$ & $3.2 \mathrm{Iab}$ & $10.78 \mathrm{ab}$ \\
$\mathrm{T}_{5}$ & $5.67 \mathrm{ab}$ & $3.45 \mathrm{ab}$ & $10.42 \mathrm{~b}$ \\
$\mathrm{~T}_{6}$ & $5.75 \mathrm{a}$ & $3.25 \mathrm{ab}$ & $10.50 \mathrm{ab}$ \\
$\mathrm{T}_{7}$ & $5.65 \mathrm{ab}$ & $3.30 \mathrm{ab}$ & $10.46 \mathrm{ab}$ \\
LSD at 0.05 & 0.16 & 0.54 & 0.76 \\
\hline
\end{tabular}

The ash content in goor was significantly influenced by the practice of integrated nutrient management treatments (Table 6) and its range varied from 2.96 to $3.57 \%$. The treatment $\mathrm{T}_{1}$ recorded significantly the highest ash content $(3.57 \%)$ and was statistically similar to all other treatments except $\mathrm{T}_{3}$ treatment and the lowest ash content $(2.96 \%)$ was observed in treatment $T_{3}$, which was statistically similar to all other treatments except $\mathrm{T}_{1}$ treatment. The increasing dose of organic fertilizers decreased ash content in juice. A similar but significant trend was recorded for ash content of goor. This showed that a higher concentration of ash in juice also increased ash in goor and a higher concentration of ash in the juice was directly proportional to higher doses of mineral fertilizers. These results of ash content in the juice were contrary to Bangar et al., ${ }^{13}$ who concluded an increase in ash with increasing press mud. But these results were analogous to Hussain et al. ${ }^{18}$ who proved that higher concentration of ash in goor was due to its higher concentration in juice.

The goor recovery (\%) was significantly influenced by the practice of integrated nutrient management treatments (Table 6). The treatment $\mathrm{T}_{3}$ significantly produced the highest goor recovery (11.21\%) among all the treatments, which was statistically similar to the treatment $\mathrm{T}_{4}$ $(10.78 \%), \mathrm{T}_{6}(10.50 \%)$ and $\mathrm{T}_{7}(10.46 \%)$. While the control treatment $\mathrm{T}_{1}$ gave significantly the lowest goor recovery $(10.13 \%)$. These results confirmed with the findings of Hussain et al. ${ }^{18}$

\section{Net rendement values}

The effects of integrated nutrient management treatments on net rendement (NR) values were significant (Table 7). Based on NRV, goor was classified into different classes such as A2 to B. Among the treatments, the $\mathrm{T}_{3}$ treatment gave significantly the highest $\mathrm{NR}$ value of goor (61.08). The second and third highest NR values were observed in $\mathrm{T}_{4}(61.0)$ and $\mathrm{T}_{6}(60.92)$ treatments. Again, the treatment $\mathrm{T}_{1}$ (control) produced the lowest value (58.67) of NR. Goor quality was higher with more of $\mathrm{A}_{1}$ quality goor with organic nutrient management practices. Similar results were reported by Keshaviah. ${ }^{19}$
Table 7 Net rendement values (NRV) of goor under different INM treatments

\begin{tabular}{lll} 
Treatments I & NR values & Grading \\
\hline $\mathrm{T}_{1}$ & $58.67 \mathrm{~g}$ & $\mathrm{~B}$ (Medium) \\
$\mathrm{T}_{2}$ & $59.98 \mathrm{~d}$ & $\mathrm{~B}$ (Medium) \\
$\mathrm{T}_{3}$ & $61.08 \mathrm{a}$ & $\mathrm{A} 2$ (Good) \\
$\mathrm{T}_{4}$ & $61.01 \mathrm{~b}$ & $\mathrm{~A} 2$ (Good) \\
$\mathrm{T}_{5}$ & $59.65 \mathrm{f}$ & $\mathrm{B}$ (Medium) \\
$\mathrm{T}_{6}$ & $60.92 \mathrm{c}$ & A2 (Good) \\
$\mathrm{T}_{7}$ & $59.93 \mathrm{e}$ & $\mathrm{B}$ (Medium) \\
$\mathrm{LSD}$ at 0.05 & 0.029 & \\
\hline
\end{tabular}

Figure(s) having common letter(s) in a column did not differ significantly at $5 \%$ level of significance

\section{Conclusion}

High yielding sugarcane production using integrated nutrient management practices is the most important strategy to nourish the rapidly growing population. From the above discussion, it is concluded that juice quality parameters such as brix, pol and purity did not vary significantly but goor quality parameters like sucrose, reducing sugars, colour transmittance, $\mathrm{pH}$ and ash varied significantly with different integrated nutrient managements. Among seven fertilizer treatments, the use of PL @ $5 \mathrm{t} \mathrm{ha}^{-1}+$ 95:51:87:9:10:2.5:4 $\mathrm{kg} \mathrm{NPKSMgZnB} \mathrm{ha-1}$ was superior on yield and quality parameters than other nutrient management treatments. It was also found that the treatment - PL@ $5 \mathrm{t} \mathrm{ha}^{-1}+$ 95:51:87:9:10:2.5:4 kg NPKSMgZnB ha- ${ }^{-1}$ followed by CD@15 tha-1 +36:52:60:17:10:2.5:4 kg NPKSMgZnB $\mathrm{ha}^{-1}$ provided an opportunity to supply raw material with better juice and goor quality of sugarcane grown in High Ganges River Floodplain soils to sugar industry and goor makers in Bangladesh.

\section{Acknowledgments}

The authors are thankful to Bangladesh Agricultural University for their financial support to conduct this study. Also grateful to Bangladesh Sugarcrop Research Institute (BSRI) for providing necessary facilities to carry out the field. We sincerely thanks to the staff of BSRI for their technical support during the implementation of the field work.

\section{Funding}

Bangladesh Agricultural University.

\section{Conflicts of interest}

The authors declare that there are no conflicts of interest.

\section{References}

1. Arefin MS, Rahman MM, Alim MA. Efficacy of organic fertilizers on the growth, yield and quality of sugarcane. Bangladesh J. Sugarcane. 2017;38:31-47.

2. Food and Agriculture Organization (FAO). Food and agriculture organization of the united nations: economic and social department: the statistical division. 2009. 567 p.

3. Nurrunnobi SM. Effects of integrated use of organic and inorganic sources of nutrition for yield maximization of rice. MS Thesis, Department of Soil Science, Mymensingh: Bangladesh Agricultural University; 2015:1-59. 
4. Gopalasundaram P, Bhaskaran A, Rakkiyappan P. Integrated Nutrient Management in Sugarcane. Sugar Tech. 2012;141:3-20.

5. Alam MJ. Productivity of sequential intercropping in paired row sugarcane. PhD Dissertation, Department of Agronomy, Mymensingh: Bangladesh Agricultural University; 2013:1-136.

6. Soomro AF, Tunio S, Oad FC, et al. Integrated effect of inorganic and organic fertilizers on the yield and quality of sugarcane (Saccharum Officinarum L). Pakstan J Bot. 2013;454:1339-1348.

7. Sarwar MA, Ibrahim M, Tahir M. et al. Appraisal of press mud and inorganic fertilizers on soil properties, yield and sugarcane quality. Pakstan J Bot. 2010;422:1361-1367.

8. Chen JCP. Cane sugar handbook. 11th edn. A Wiley-Interscience Publication, New York:John Wiley \& Sons; 1985:1101-1103.

9. Anonymous. Laboratory manual for queensland sugar mills. 5th edn Queensland: Division of Mill Technology Brisbane; 1970:94-143.

10. Varma NC. System of technical control for cane sugar factories in India. Revised edn, Kanpur, India: The Sugar Technologists Association of India; 1988:17-35.

11. Jabber MA. Jaggery (Goor): manufacture and quality control. MS Thesis, Department of Food Technology, Karnataka, India: University of Mysore; 1982:1-75.

12. Gomez KA, Gomez AA. Statistical procedures for agricultural research 2nd edn. New York, USA: A Wiley-Interscience publication; 1984:442443.
13. Bangar KS, Parmar BB, Maini A. Effect of fertilizers nitrogen and press mud cake on growth, yield and quality of sugarcane. Crop Res. (Hisar), 1994;8(1):23-27.

14. Bokhtiar SM, Sakurai K. Integrated use of organic manures and chemical fertilizers on growth, yield and quality of sugarcane in high ganges river floodplain soils of Bangladesh. J Commun Soil Sc \& Plant Anal. 2007;36:1823-1837.

15. Bokhtiar SM, Sakurai K. Effect of application of inorganic and organic fertilizers on growth, yield and quality of sugarcane. Sugar Tech. $2005 ; 7: 33-37$

16. Mohammad BD. Effect of nitrogen fertilizer and harvest time on yield and quality of sugarcane. M.Sc. Thesis, Agron Departmrnt, Egypt: Assiut University; 1989.

17. Bokhtiar SM, Paul GC, Alam KM. Effects of organic and inorganic fertilizers on growth, yield, juice quality and residual effects on ratoon crops of sugarcane. J Plant Nutri. 2008;31:1832-1843.

18. Hussain F, Sarwar MA, Chattha AA. Screening of some sugarcane genotypes for goor quality. J Anim Plant Sci. 2007;17:76-78.

19. Keshavaiah KV. Effect of organic and integrated nutrient management on growth, yield and quality of sugarcane and jaggery in cauvery command area. PhD Thesis, Department of Agronomy, College of Agriculture, Dharwad: Dharwad University of Agricultural Science; 2011:1-168.

20. Arefin MS, Rahman MM, Alim MA, et al. Influence of integrated nutrient management practices on the juice and Goor quality of sugarcane. PSJ (January-March). XXXV 2020;(1):10-20. 